\title{
Dietary Sodium Intake and Serum Uric Acid: A Mini-Review
}

\section{Lei Lei Ji-Guang Wang}

Centre for Epidemiological Studies and Clinical Trials, Shanghai Key Laboratory of Hypertension, The Shanghai Institute of Hypertension, Department of Hypertension, Ruijin Hospital, Shanghai Jiaotong University School of Medicine, Shanghai, China

\section{Keywords}

Dietary sodium intake $\cdot$ Serum uric acid $\cdot$ Hypertension $\cdot$ Kidney

\begin{abstract}
The aim of the present review is to summarize recent studies on the relationship between dietary sodium intake and serum uric acid concentration. In short-term dietary sodium intervention studies, including a recent further analysis of a previously published trial, high dietary sodium intake ( $200 \mathrm{mmol} /$ day), compared with a low sodium diet $(20-60 \mathrm{mmol} / \mathrm{day})$, resulted in a significant reduction in serum uric acid, being approximately $20-60 \mu \mathrm{mol} / \mathrm{L}$. This finding, though consistent across short-term studies, is in contradiction to the long-term observational evidence on the relationship between dietary sodium intake and serum uric acid. Indeed, in a population-based prospective study, high dietary sodium intake was associated with a higher serum uric acid concentration. If serum uric acid would be followed up, several currently ongoing long-term randomized dietary sodium intervention studies may shed some light on how dietary sodium intake interacts with serum uric acid in the development of hypertension.

(C) 2018 S. Karger AG, Basel
\end{abstract}

Uric acid is an end product of purine metabolism in humans. It is a well-recognized major antioxidant in the human body. However, it increases in hypertension and other cardiovascular diseases [1,2]. Indeed, prospective studies demonstrated that hyperuricemia was associated with the incidence of hypertension [3] and cardiovascular mortality and morbidity [4, 5]. Some researchers believe that hyperuricemia may be a pathogenic factor for human hyper-

Ji-Guang Wang, MD, PhD

The Shanghai Institute of Hypertension

Ruijin 2nd Road 197

Shanghai 200025 (China)

E-Mail jiguangwang @aim.com 
tension [6]. There is some evidence that uric acid-lowering therapy may reduce the blood pressure in adolescents with hypertension [7] or prehypertension [8] in the presence of hyperuricemia $[7,8]$.

Despite epidemiological, experimental, and clinical trial evidence on the relationship between serum uric acid and human hypertension, the topic remains controversial [9]. One of the reasons is that serum uric acid lowering has very little or almost no blood pressurelowering effect in hypertensive adults $[10,11]$ and no effect on endothelial function [9]. It is therefore postulated that the relationship between serum uric acid and hypertension may be mediated by other risk factors of hypertension rather than a direct causal one. After filtration of uric acid from the glomerulus, it may be reabsorbed in the renal tubules in parallel with sodium reabsorption. That is exactly the mechanism that thiazide diuretics increase serum uric acid via increasing sodium-uric acid reabsorption in the proximal tubule as a biofeedback of the thiazide-inhibited sodium reabsorption in the distal tubule [12]. Excessive dietary sodium intake is a major risk factor of human hypertension. Sodium intake and reabsorption is therefore most likely the mediator between serum uric acid and hypertension.

There is some prospective observational evidence on the interaction between sodium intake and serum uric acid in relation to the incidence of hypertension [13]. In a large ( $n=$ 4,062), population-based long-term follow-up (5-9 years) study, higher sodium intake at baseline was associated with a significantly higher increase in serum uric acid concentration during follow-up $(1.2 \mu \mathrm{mol} / \mathrm{L}$ per $1 \mathrm{~g}$ higher sodium intake at baseline, 95\% confidence interval [CI] 0.2-2.6) and a significantly higher incidence of hypertension only in the top tertile of serum uric acid concentration at baseline (hazard ratio 1.09 per $1 \mathrm{~g}$ higher sodium intake, 95\% CI 1.02-1.16) [13]. The investigators of the study interpreted the increased serum uric acid as a marker of endothelial dysfunction instead of a risk factor of hypertension. The observational nature of the study does not allow any causal inference. Nonetheless, the study clearly demonstrated some relationship between dietary sodium intake and the metabolism of uric acid.

There is a need of intervention trials to clarify the relationship between sodium intake and serum uric acid. A number of short-term (1 week to 1 month) intervention studies investigated effects of various levels of dietary sodium intakes on serum uric acid concentration (Table 1) [14-17]. The results of these studies were consistent. In these studies, high dietary sodium intake was approximately $200 \mathrm{mmol} /$ day or $12 \mathrm{~g}$ of sodium chloride, and restricted low dietary sodium intake approximately $20 \mathrm{mmol} /$ day or $1.2 \mathrm{~g}$ of sodium chloride. High dietary sodium intake, compared with low sodium intake, reduced the serum uric acid concentration by $20-60 \mu \mathrm{mol} / \mathrm{L}(0.3-1.0 \mathrm{mg} / \mathrm{dL}$ ) from approximately 300 to $400 \mu \mathrm{mol} / \mathrm{L}$ (5.0 to 6.7 $\mathrm{mg} / \mathrm{dL}$ ) [14-17].

In a recent publication, Todd et al. [18] performed further analysis of the data from a previously published dietary sodium intervention study in 22 normotensive subjects and 30 hypertensive patients [19]. In a 4-week randomized cross-over study on high versus medium versus low levels of dietary sodium intakes, a moderate (150 mmol/day) and high (200-250 $\mathrm{mmol} /$ day) sodium diet, compared with a low sodium diet ( $60 \mathrm{mmol} /$ day, mean $[ \pm \mathrm{SD}]$ serum uric acid concentration $300 \pm 70 \mu \mathrm{mol} / \mathrm{L}$ ), caused a statistically significant reduction in the serum uric acid concentration $(-22 \mu \mathrm{mol} / \mathrm{L}, 95 \% \mathrm{CI}-28$ to -16 and $-24 \mu \mathrm{mol} / \mathrm{L}, 95 \% \mathrm{CI}-27$ to -17 , respectively). High sodium intake was also associated with a higher urinary sodium/ creatinine ratio, lower plasma renin activity, lower serum aldosterone concentration and aldosterone/renin ratio and a higher systolic and diastolic blood pressure [18].

The results of these short-term studies are in line with the observation of a much earlier experimental study in a group of 24 normotensive and hypertensive subjects during the expansion of extracellular fluid volume with intravenous infusions of hypertonic saline [20]. In this study, acute sodium loading increased urinary excretions of sodium and uric acid 


$\begin{array}{lll}1 & 1\end{array}$

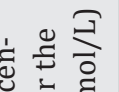

₹

\section{올}

뇽

$\therefore$

o

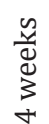

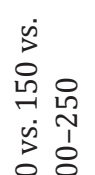

옹

$\stackrel{\llcorner}{\sim}$ 


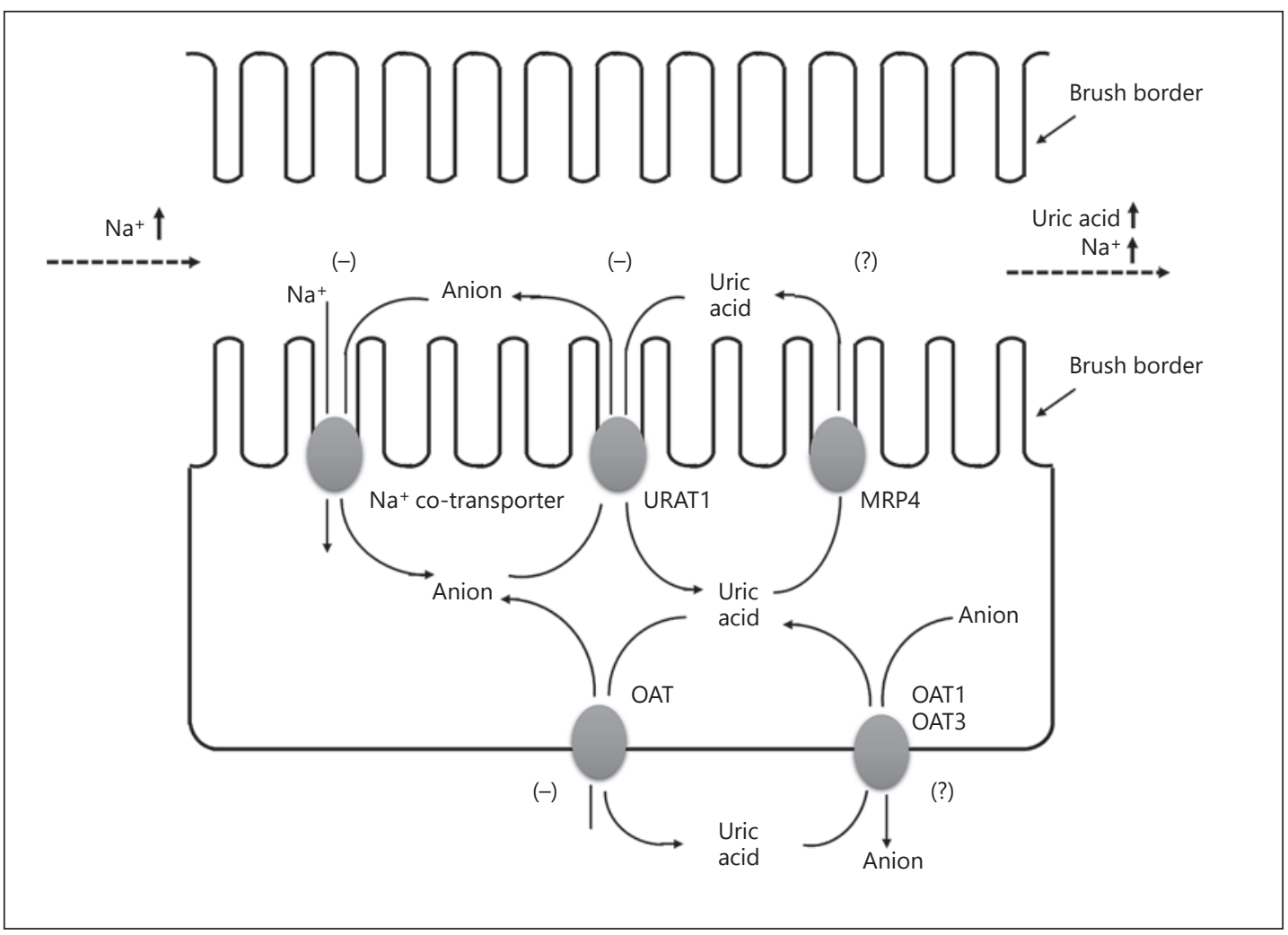

Fig. 1. Possible mechanism for the increased urinary excretion of uric acid as a consequence of an increased sodium dietary intake and glomerular filtration into the renal tubules. (-), action of "inhibition"; (?), action "unknown"; URAT 1, urate transporter; MRP4, multidrug resistance protein; OAT, organic anion transporter.

(correlation coefficient 0.731$)$ and resulted in a $36.9 \mu \mathrm{mol} / \mathrm{L}(0.62 \mathrm{mg} / \mathrm{dL})$ reduction in the serum uric acid concentration [20]. However, the results of the short-term studies seemed to be contradictory to the observational evidence from the abovementioned long-term prospective study [13]. To clarify this issue, long-term randomized dietary sodium intervention studies are required. In fact, several such studies are currently ongoing [21, 22]. If serum uric acid would be followed up, these studies might shed some light on the relationship between dietary sodium intake and urinary excretion of uric acid. Before such evidence is readily available, one of the speculative mechanisms might be that the increased urinary excretion of uric acid as a consequence of increased dietary sodium intake in the long run impairs kidney function and finally results in a high serum concentration of uric acid (Fig. 1). There is indeed abundant evidence on the detrimental effect of high urinary excretion of uric acid on kidney function [23] and on high serum uric acid as an indicator of impaired kidney function [24]. The urate salt, especially in the form of calcium salt, may become calculi or crystalline in the kidney and damage the function of the kidneys [23]. Impaired renal function may influence sodium metabolism and increase the risk of hypertension.

Other dietary factors or treatment with thiazide diuretics may also confound or contribute to the interaction between dietary sodium intake and the serum concentration and urinary excretion of uric acid. The currently ongoing long-term randomized dietary sodium intervention studies were not specifically designed to address this issue, and post hoc analyses can only be hypothesis generating. 
Future research might have to rely on measurements of both serum concentration and urinary excretion of uric acid to investigate the role of uric acid in hypertension while accounting for sodium intake and excretion [25]. One research question may be whether to any extent long-term high dietary sodium intake would increase the blood pressure and the incidence of hypertension via increasing the urinary excretion of uric acid and impairing renal function. Another question is whether a high serum concentration of uric acid and high glomerular filtration of uric acid would influence tubular reabsorption of sodium in parallel with uric acid and induce the so-called sodium-sensitive hypertension. Because of the epidemic of a high-salt diet and high serum uric acid in almost all populations, it is important to illustrate the mechanisms for the interaction between sodium intake and the metabolism of uric acid in relation to hypertension, which is an increasing health burden in our modern society, regardless of high or low-middle incomes.

\section{Disclosure Statement}

Dr. Wang reports having received grants from the National Natural Science Foundation of China (81270373, 81470533, and 91639203), the Ministry of Science and Technology (2015AA020105-06 and 2016YFC1300100), and the Shanghai Commission of Science and Technology (15XD1503200) and lecture and consulting fees from Astra-Zeneca, Bayer, Daiichi-Sankyo, MSD, Omron, Pfizer, Sanofi, Servier, and Takeda. Dr. Lei declares no conflict of interest.

\section{References}

1 Mallat SG, Al Kattar S, Tanios BY, Jurjus A: Hyperuricemia, hypertension, and chronic kidney disease: an emerging association. Curr Hypertens Rep 2016;18:74.

2 Kuwabara M: Hyperuricemia, cardiovascular disease, and hypertension. Pulse (Basel) 2016;3:242-52.

3 Han T, Lan L, Qu R, Xu Q, Jiang R, Na L, Sun C: Temporal relationship between hyperuricemia and insulin resistance and its impact on future risk of hypertension. Hypertension 2017;70:703-711.

4 Wang JG, Staessen JA, Fagard RH, Birkenhäger WH, Gong L, Liu L, for the Systolic Hypertension in China (SYSTChina) Collaborative Group: Prognostic significance of serum creatinine and uric acid in older Chinese patients with isolated systolic hypertension. Hypertension 2001;37:1069-1074.

5 Wang JG, Staessen JA: Raised concentrations of serum creatinine and uric acid and the risks of mortality and cardiovascular disease. Cardiovasc Rev Rep 2002;23:393-399, 402.

6 Feig DI, Madero M, Jalal DI, Sanchez-Lozada LG, Johnson RJ: Uric acid and the origins of hypertension. J Pediatr 2013;162:896-902.

7 Feig DI, Soletsky B, Johnson RJ: Effect of allopurinol on blood pressure of adolescents with newly diagnosed essential hypertension: a randomized trial. JAMA 2008;300:924-932.

8 Soletsky B, Feig DI: Uric acid reduction rectifies prehypertension in obese adolescents. Hypertension 2012; 60:1148-1156.

9 Borgi L, McMullan C, Wohlhueter A, Curhan GC, Fisher ND, Forman JP: Effect of uric acid-lowering agents on endothelial function: a randomized, double-blind, placebo-controlled trial. Hypertension 2017;69:243-248.

10 Gunawardhana L, McLean L, Punzi HA, Hunt B, Palmer RN, Whelton A, Feig DI: Effect of febuxostat on ambulatory blood pressure in subjects with hyperuricemia and hypertension: a phase 2 randomized placebocontrolled study. J Am Heart Assoc 2017;6:e006683.

11 Kim HA, Seo YI, Song YW: Four-week effects of allopurinol and febuxostat treatments on blood pressure and serum creatinine level in gouty men. J Korean Med Sci 2014;29:1077-1081.

12 Weinman EJ, Steplock D, Suki WN, Eknoyan G: Urate reabsorption in proximal convoluted tubule of the rat kidney. Am J Physiol 1976;231:509-515.

13 Forman JP, Scheven L, de Jong PE, Bakker SJ, Curhan GC, Gansevoort RT: Association between sodium intake and change in uric acid, urine albumin excretion, and the risk of developing hypertension. Circulation 2012; 125:3108-3116.

14 Egan BM, Weder AB, Petrin J, Hoffman RG: Neurohumoral and metabolic effects of short-term dietary $\mathrm{NaCl}$ restriction in men. Relationship to salt-sensitivity status. Am J Hypertens 1991;4:416-421.

15 Del Río A, Rodríguez-Villamil JL: Metabolic effects of strict salt restriction in essential hypertensive patients. J Inter Med.1993;233:409-414.

16 Todd AS, Macginley RJ, Schollum JB, Johnson RJ, Williams SM, Sutherland WH, Mann JI, Walker RJ: Dietary salt loading impairs arterial vascular reactivity. Am J Clin Nutr 2010;91:557-564. 
17 Juraschek SP, Gelber AC, Choi HK, Appel LJ, Miller ER 3rd: Effects of the Dietary Approaches to Stop Hypertension (DASH) diet and sodium intake on serum uric acid. Arthritis Rheumatol 2016;68:3002-3009.

18 Todd AS, Walker RJ, MacGinley RJ, Kelly J, Merriman TR, Major TJ, Johnson RJ: Dietary sodium modifies serum uric acid concentrations in humans. Am J Hypertens 2017;30:1196-1202.

19 Todd AS, Macginley RJ, Schollum JB, Williams SM, Sutherland WH, Mann JI, Walker RJ: Dietary sodium loading in normotensive healthy volunteers does not increase arterial vascular reactivity or blood pressure. Nephrology (Carlton) 2012;17:249-256.

20 Cannon PJ, Svahn DS, Demartini FE: The influence of hypertonic saline infusions upon the fractional reabsorption of urate and other ions in normal and hypertensive man. Circulation 1970;41:97-108.

21 Li N, Yan LL, Niu W, Labarthe D, Feng X, Shi J, Zhang J, Zhang R, Zhang Y, Chu H, Neiman A, Engelgau M, Elliott $\mathrm{P}, \mathrm{Wu} Y$, Neal B: A large-scale cluster randomized trial to determine the effects of community-based dietary sodium reduction - the China Rural Health Initiative Sodium Reduction Study. Am Heart J 2013;166:815-822.

22 Neal B, Tian M, Li N, Elliott P, Yan LL, Labarthe DR, Huang L, Yin X, Hao Z, Stepien S, Shi J, Feng X, Zhang J, Zhang Y, Zhang R, Wu Y: Rationale, design, and baseline characteristics of the Salt Substitute and Stroke Study (SSaSS)-A large-scale cluster randomized controlled trial. Am Heart J 2017;188:109-117.

23 Abou-Elela A: Epidemiology, pathophysiology, and management of uric acid urolithiasis: a narrative review. J Adv Res 2017;8:513-527.

24 Messerli FH, Frohlich ED, Dreslinski GR, Suarez DH, Aristimuno GG: Asymptomatic mild hyperuricaemia: an indicator of nephrosclerosis in essential hypertension. Clin Sci (Lond) 1980;59(suppl 6):409s-410s.

25 Mrug S, Mrug M, Morris AM, Reynolds N, Patel A, Hill DC, Feig DI: Uric acid excretion predicts increased blood pressure among American adolescents of African descent. Am J Med Sci 2017;353:336-341. 